\section{Dementia risk factors for Australian baby boomers}

\author{
Peter K. Panegyres, Victoria Gray \\ Neurodegenerative Disorders Research, \\ Subiaco, Western Australia
}

\section{Abstract}

Baby boomers are individuals born in the years 1946 to 1965. The objective of this paper was to define the risk factors for dementia and Alzheimer's disease (AD) and their relevance to Australian baby boomers, with the aim of providing evidence-based guidelines for dementia prevention. A series of PubMed searches (1994-2010) were conducted with relevant key words. Data was included from the Australian Bureau of Statistics (ABS) in relation to baby boomers in Australia. Article titles and abstracts were assessed by two reviewers for inclusion. Searches through ABS revealed no specific study on baby boomers at a national level; information was only available for Western Australia, South Australia and Queensland. A number of genetic and nongenetic risk factors for dementia were identified most of which remain controversial and require further study. We did not identify significant differences in the prevalence and incidence of dementia in those under 65 years in Queensland, South Australia and Western Australia. There were no correlations of risk factors and dementia between the Australian states. Modification of risk factors has not been proven to reduce the incidence and prevalence of dementia and $\mathrm{AD}$ in baby boomers. Nevertheless, on available evidence, we recommend: i) active management of cardiovascular risk factors such as hypertension; ii) the encouragement of a healthy lifestyle (eg, weight reduction, exercise) as offering the best pathways to reduce the emerging dementia risk for baby boomers. The implications are that activities promoting a healthy heart might lead to a healthy brain and help to prevent dementia.

\section{Introduction}

Dementia is one of the most important problems facing our society. The recent US study '2008 Alzheimer's Disease Facts and Figures' from the authors of the Framingham Heart Study reveals that Alzheimer's disease (AD) and dementia have outstripped cancer and stroke as a more common cause of death. ${ }^{1} \mathrm{We}$ are concerned that this change not only represents a shift in assessment and treatment of cancer and stroke, but displays the importance of identifying risk factors for AD and dementia. The United States Alzheimer's Disease study showed that the baby boom generation, which is defined as residents born between the years of 1946 to 1965 , seem to be at particular risk of developing $\mathrm{AD}$ or dementia. Of the 78 million baby boomers in America, at least 10 million are expected to get dementia in their remaining lifetime. ${ }^{1}$ Based on the percentage of baby boomers in Western Australia, South Australia and Queensland, we estimate the percentage of baby boomers at an Australian National level to be $29 \%$ of a total population of approximately 21.5 million. Therefore, of the estimated $6,235,000$ baby boomers in Australia, at least 798,000 are expected to develop dementia in their lifetime, if Australia follows the United States trend, posing enormous economic costs and challenges to the health care system. The US trend towards increased risk of developing dementia is likely to be similar for Australia's baby boomers on account of epidemiological trends reported by the Australian Bureau of Statistics (ABS) for Western Australian, South Australia and Queensland. ${ }^{2}$ There are no data available on the most populated states of Victoria and New South Wales. The epidemiological trends include risk factors such as smoking, obesity and sedentary life style. This paper further defines the risk factors for dementia and $\mathrm{AD}$ and how they might be correctable in the future. The aim is to provide evidence-based guidelines for dementia prevention in the 21 st century as relevant to the Australian population.

\section{Materials and Methods}

The PubMed database was interrogated from 1994-2010 using key words of dementia, Alzheimer's disease, baby boomers and evidence-based guidelines. Articles were assessed by two reviewers for inclusion based on methods and relevance. The Australian Bureau of Statistics (ABS) makes information publicly available on their website and information was identified for Western Australia, South Australia and Queensland. The ABS did not possess information at the time of the study for the other states or for the nation as a whole.

\section{Results}

\section{Alzheimer's Disease Facts and Figures: USA}

The recent 2008 Alzheimer's Disease USA study states the problem in the United States
Correspondence: Peter K. Panegyres, Neurodegenerative Disorders Research Pty Ltd, 185 York Street, Subiaco, Western Australia 6008.

E-mail: publications@panegyres.com.au

Key words: dementia, Alzheimer's disease, baby boomers, evidence-based guidelines.

Acknowledgments: York Neuroscience Discovery Inc supported this project.

Received for publication: 27 January 2010.

Revision received: 18 May 2010.

Accepted for publication: 19 May 2010.

This work is licensed under a Creative Commons Attribution 3.0 License (by-nc 3.0).

CCopyright P.K. Panegyres and V. Gray, 2010

Licensee PAGEPress, Italy

Neurology International 2010; 2:e13

doi:10.4081/ni.2010.e13

where it is estimated that 10 million ( 1 in 8 ) American baby boomers will develop AD. ${ }^{1}$ Currently in 2008 an estimated 5.2 million Americans of all ages have $\mathrm{AD}$, with about one in 8 people older than 65 (approximately 13\%) having the disease. ${ }^{1}$ Women are more likely to develop $\mathrm{AD}$ than men, probably because they live longer. ${ }^{3}$ Therefore, the female gender itself is not a risk factor once age is considered. The lifetime risk for $\mathrm{AD}$ cannot be predicted from birth; however, the lifetime risk of developing $\mathrm{AD}$ is one in 6 for women and in 10 for men who live to be at least 55 (Figure 1A). The remaining lifetime risk of any dementia, including $\mathrm{AD}$ for women and men is higher than that of $\mathrm{AD}$ alone (Figure 1B). This lifetime risk of dementia and $\mathrm{AD}$ will substantially increase in the future unless there are new preventative treatments. This study raises implications for the 78 million baby boomers in America, of which it is estimated that 10 million can expect to develop AD in their remaining lifetime. The authors note that these are conservative estimates due to the nature of data and that the true lifetime risk to baby boomers would actually be greater. As many as half a million new cases will develop every year by 2010 . By 2050 that number is expected to grow to one million. The years 2000 to 2005 have seen the decline in death rates of heart disease, breast cancer, prostate cancer and stroke; however, the rates of $\mathrm{AD}$ have increased by almost $45 \%$ (Figure 1C). This decline in death rates from other causes of death could further increase rates on dementia as people live longer. Currently $\mathrm{AD}$ is among the top 10 leading causes of death for people of all ages, and number 5 for those 65 years and older. However, it is important to note that $\mathrm{AD}$ and dementias co-exist with other medical conditions, including hypertension, coronary 
(A) Alzheimer's disease

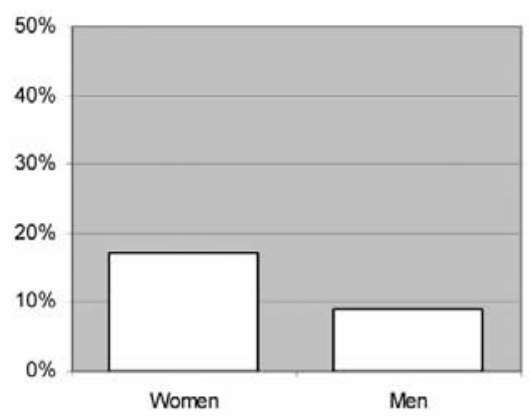

(B) Dementia

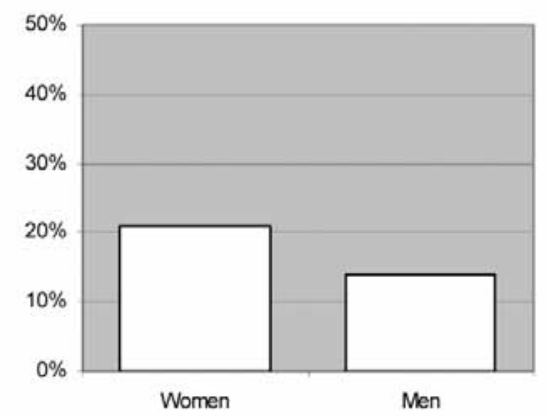

(C) Leading causes of death

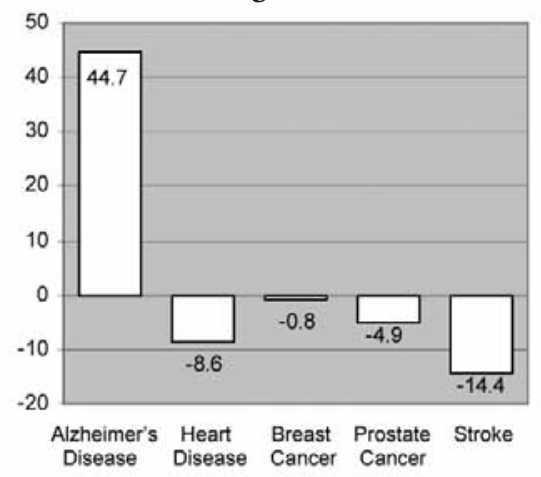

Figure 1. (A) Percentage of women and men who will develop Alzheimer's disease in their remaining lifetime if they live to be at least age 55, Framingham Heart Study. (B) Percentage of women and men who will develop dementia in their remaining lifetime if they live to be at least age 55, Framingham Heart Study. (C) Percentage change in leading causes of death from 2000 to 2005.

Source: Alzheimer's Association, 2008 Alzheimer's Disease Facts and Figures.'

artery disease, cognitive heart failure and others. ${ }^{4}$ The AD USA study also shows that people with fewer years of education are more likely to develop AD and dementia, a finding supported by other studies..$^{5-8}$ Importantly, the implications of $\mathrm{AD}$ on health care, long-term care and end-of-life care services are of great concern. Most individuals develop $\mathrm{AD}$ and other dementias as a co-morbidity with one or more other serious medical conditions. Financial and emotional costs of this disease, with particular attention to carers, must also be emphasized. ${ }^{9}$

\section{The demography of Australian baby boomers}

An overview of the epidemiology of Australia's baby boomers based on the Australian Bureau of Statistics (ABS) data raises concern over their risk of developing $\mathrm{AD}$ and dementia. According to the ABS, the baby boom generation refers to all Australian residents born in the years 1946 to 1965, including those who migrated to Australia from countries which did not experience the baby boom. ${ }^{2}$ The total percentage of baby boomers in Australia is $28.7 \%$. Figure 2 shows the Population Pyramid of Australia in 2003 and the ages of the baby boomers. ${ }^{10}$ Three separate ABS studies specific to baby boomers in Western Australia, ${ }^{11}$ South Australia ${ }^{12}$ and Queensland ${ }^{13}$ have been identified from which we have made assumptions pertaining to the whole of Australia. For the purposes of this paper the most important results of these studies were those of self-assessed health status, smoking status, alcohol consumption and exercise patterns, as they are potential risk factors for $\mathrm{AD}$ and correctable in the future (Table 1). In 2001, Western Australia's 557,000 baby boomers were aged 36 to 55 years and made up $29 \%$ of the population. In South Australia $29 \%$ of the population was also made up of baby boomers $(441,300)$. Nearly one in

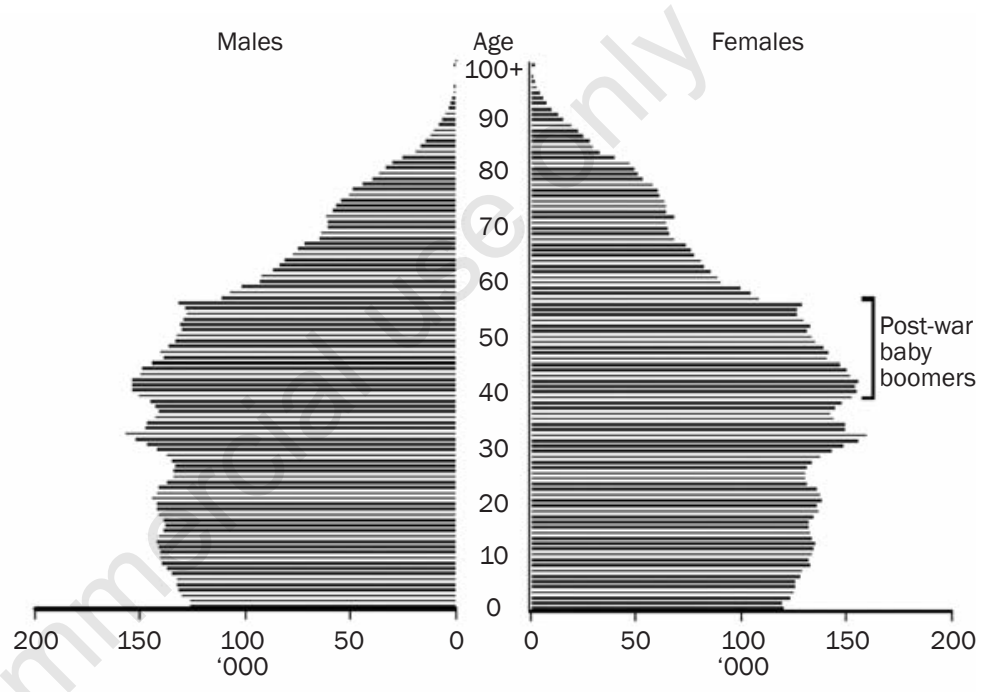

Figure 2. Population pyramid of Australian states and territories.

Source: 2003 ABS cat. no. 3201.0.10

three Queenslanders (29\%) are baby boomers $(1,039,000)$ and this percentage is set to grow dramatically over the coming years. Of all the baby boomers in $2001,25 \%, 26 \%$ and $28 \%$ from Western Australia, South Australia and Queensland, respectively, were smokers. In Western Australia, two-thirds of baby boomers were inactive or undertaking low levels of exercise. In Queensland and South Australia, $71 \%$ and $73 \%$, respectively, were sedentary or undertaking low levels of exercise. In Western Australia, Queensland and South Australia, more than $50 \%$ were overweight or obese. The percentage of baby boomers exhibiting risky or high-risk levels of alcohol consumption in Western Australia, Queensland and South Australia were $14 \%, 13.1 \%$, and $11.5 \%$, respectively. While in Western Australia (83\%), Queensland (82\%) and South Australia (79\%) a high percentage of baby boomers reported a self-assessed health status of good, very good or excellent, there were higher proportions reporting long-term health conditions. In both Queensland and Western Australia, high cholesterol and hypertensive disease were more frequently reported by older baby boomers than by younger baby boomers. In Queensland and Western Australia, high cholesterol in older baby boomers was $11 \%$ and $13.6 \%$, respectively. In younger baby boomers it was $4 \%$ and 5.6\%, respectively. In Queensland and Western Australia hypertensive disease was $15 \%$ and $13.9 \%$ in that order for older baby boomers; in younger baby boomers it was $4.2 \%$ and $4.6 \%$, respectively. Using a non-parametric analysis of variance there were no significant differences between the three states and health risk factors as listed in Table 1 [Kruskal-Wallis statistic $=3.611$, corrected for ties and approximated using $\left.\chi^{2}, \mathrm{P}=0.1644\right]$. Access Economics have collated incidence and prevalence data for domestic Australia and its states. ${ }^{14}$ The 
Table 1. Health risk factors of baby boomers: Western Australia, South Australia and Queensland.*

\begin{tabular}{lccc} 
& Western Australia & South Australia & Queensland \\
& $(2001)$ & $(2001)$ & $(2001)$ \\
\hline Number of baby boomers & 557,700 & 441,000 & $1,039,000$ \\
Younger (born 1956-65) & 297,300 & 231,000 & 549,300 \\
\hline Older (born 1946-55) & 260,400 & 210,000 & 489,500 \\
Self assessed health status- excellent/very good & 281,900 & 221,300 & 534,000 \\
Younger (born 1956-65) & 160,200 & 119,700 & 291,600 \\
Self assessed health status- good & 178,000 & 122,200 & 322,100 \\
\hline Younger (born 1956-65) & 96,600 & 74,900 & 96,000 \\
Older (born 1946-55) & 81,400 & 47,300 & 104,700 \\
\hline Self assessed health status- fair/poor & 81,100 & 91,400 & 182,900 \\
Younger (born 1956-65) & 29,100 & 31,200 & 28,500 \\
\hline Older (born 1946-55) & 52,000 & 60,100 & 36,400 \\
Current smoker & 134,400 & 115,000 & 290,900 \\
\hline Younger (born 1956-65) & 82,500 & 67,900 & 93,100 \\
Older (born 1946-55) & 51,900 & 47,100 & 66,900 \\
\hline Risky/high risk alcohol consumption & 74,700 & 51,300 & 136,100 \\
Younger (born 1956-65) & 37,200 & 21,300 & $\mathrm{~N} / \mathrm{A}$ \\
\hline Older (born 1946-55) & 37,500 & 30,000 & $\mathrm{~N} / \mathrm{A}$ \\
Sedentary/low exercise & 358,600 & 323,200 & 322,100 (Sedentary) \\
\hline Younger (born 1956-65) & 183,100 & 172,400 & $\mathrm{~N} / \mathrm{A}$ \\
Older (born 1946-55) & 175,500 & 150,800 & $\mathrm{~N} / \mathrm{A}$ \\
\hline Overweight/obese & 276,700 & 221,800 & 561,100 \\
Younger (born 1956-65) & 142,000 & 109,900 & 279,400 \\
\hline Older (born 1946-55) & 134,600 & 111,900 & 328,800 \\
\hline High cholesterol & & & \\
\hline Younger (born 1956-65) & 16,600 & $\mathrm{~N} / \mathrm{A} / \mathrm{A}$ & 22,000 \\
Older (born 1946-55) & 35,400 & 53,800 \\
\hline Hypertensive disease & & & \\
Younger (born 1956-65) & 12,500 & 25,300 \\
\hline Older (born 1946-55) & & \\
\hline Non, & & \\
\hline
\end{tabular}

* Non-parametric ANOVA $=3.611 ; \mathrm{P}=0.1644$.

prevalence and incidence data for Queensland, South Australia and Western Australia are shoen in Tables 2 and 3, respectively. Using a non-parametric analysis of variance there are no statistically significant differences between these states of Australia and the prevalence and incidence of dementia [prevalence: Kruskal-Wallis $=3.567, \mathrm{P}=0.1964$; incidence Kruskal-Wallis $=5.333, \mathrm{P}=0.0714]$.

\section{Discussion}

\section{Dementia risk factors: the evidence base}

High systolic blood pressure has been reported as a risk factor for dementia. The Kungsholmen Project ${ }^{15}$ found that patients with high blood pressure greater than 180
$\mathrm{mmHg}$ had a $50 \%$ increase of developing $\mathrm{AD}$ and dementia (Table 4). A risk score for the prediction of dementia based on risk factors at mid-life found high systolic blood pressure to significantly predict dementia. ${ }^{16}$ Low diastolic pressure less than $65 \mathrm{mmHg}$ led to a $40 \%$ increased risk of developing AD or dementia. ${ }^{15}$ The Kungsholmen Project found that heart failure was associated with an over $80 \%$ increased risk of dementia and AD. ${ }^{15}$ Men with unrecognized myocardial infarction are at increased risk of dementia and cerebral small vessel disease. ${ }^{36}$ This was not so in women. Results of the Whitehall II study suggest an association between coronary heart disease and cognitive performance in middle-aged adults. ${ }^{31}$ As indicated in the Kungsholmen Project, ${ }^{15}$ use of antihypertensive drugs may decrease risk of dementia and $\mathrm{AD},{ }^{33}$ as they may counteract the combined effect on dementia due to the genetic risk factors APOE\&4 and
Table 2. Prevalence of dementia in individuals aged under $65\left(\times 10^{3}\right)$.*

\begin{tabular}{lccc} 
Gender Queensland & $\begin{array}{c}\text { South } \\
\text { Australia }\end{array}$ & $\begin{array}{c}\text { Western } \\
\text { Australia }\end{array}$ \\
Male & 1.25 & 0.49 & 0.62 \\
Female & 0.71 & 0.29 & 0.34 \\
\hline Total & 1.96 & 0.78 & 0.96 \\
\hline * Non-parametric ANOVA $=3.467, \mathrm{P}=0.1964$.
\end{tabular}

Table 3. Incidence of dementia in individuals aged under $65\left(\times 10^{3}\right)$.*

\begin{tabular}{lccc} 
Gender Queensland & $\begin{array}{c}\text { South } \\
\text { Australia }\end{array}$ & $\begin{array}{c}\text { Western } \\
\text { Australia }\end{array}$ \\
Male & 0.10 & 0.04 & 0.05 \\
Female & 0.10 & 0.04 & 0.05 \\
\hline Total & 0.20 & 0.08 & 0.10 \\
\hline * Non-parametric ANOVA $=5.333, \mathrm{P}=0.0714$.
\end{tabular}

Table 4. Dementia risk factors: evidencebase.

High blood pressure ${ }^{15-17}$

Obesity/high BMI 16,18,19

Smoking 15,20,21

Alcohol ${ }^{15,20}$

Head injury ${ }^{22-24}$

Low cognitive activity ${ }^{25: 30}$

Low physical activity ${ }^{19}$

Non-steroidal anti-inflammatory drugs ${ }^{31}$

History of coronary heart disease ${ }^{15,32}$

Antihypertensive drugs ${ }^{15,17,33,34}$

Diabetes mellitus ${ }^{35}$

Cholesterol ${ }^{16}$

Genetic: APOE $\varepsilon 4^{16,20}$ high systolic blood pressure. ${ }^{34}$ A study using the Hypertension in the Very Elderly Trial cognitive function assessment (HYVET-COG) found that antihypertensive treatment in elderly patients does not statistically reduce the incidence of dementia; however, this may be due to early follow up. The authors indicate that the HYVET findings, when included in a meta-analysis, might support antihypertensive treatment to reduce incident dementia. ${ }^{17}$ Some studies indicate that treatment of dementia might slow cognitive decline and prevent AD ${ }^{37,38}$ A study by Xu et al. ${ }^{35}$ found that diabetes mellitus increases the risk of dementia in very old people even after adjusting for other confounders. There seems to be an association between type 2 diabetes and APOE\&4 allele, and increased risk of developing $\mathrm{AD}{ }^{39}$ High Body Mass Index was found to be a significant predictor of dementia indicated by the risk score as per Kivipelto et al. ${ }^{16}$ Whitmer et al. ${ }^{18}$ 
found that central obesity in mid-life increases risk of dementia independent of diabetes and cardiovascular co-morbidities. High cholesterol was found to be a significant predictor of dementia indicated by the risk score as per Kivipelto et al. ${ }^{16}$ Use of statins has been associated with reduced risk of incident dementia and $\mathrm{AD} .{ }^{40,41}$ Heavy drinking and smoking were associated with reduced age of onset of Late Onset Alzheimer's Disease (LOAD), with data suggesting that the elimination of smoking and heavy drinking could substantially reduce the age-specific prevalence of LOAD. ${ }^{20}$ Life habits such as smoking and alcohol were also found to be associated with an increased risk of dementia and $\mathrm{AD}$ in the Kungsholmen Project. ${ }^{15}$ Current smoking was found to increase the risk of dementia which was more pronounced in persons without the $\mathrm{APOE} \varepsilon 4$ allele than APOE\&4 carriers. $^{21}$ More frequent participation in cognitive activity was associated with reduced incidence of AD. A cognitively inactive person was 2.6 times more likely to develop $\mathrm{AD}$ than a cognitively active person..$^{25} \mathrm{~A}$ number of other studies have also shown that greater cognitive activity is associated with reduced cognitive decline in mild cognitive impairment, ${ }^{25-27}$ dementia or AD. ${ }^{28-30}$ According to Andel et al. ${ }^{19}$ it was found that exercise at mid-life may reduce odds of dementia in older adulthood, suggesting that exercise interventions should be explored as a potential strategy for delaying disease onset. ${ }^{42}$ Vlad et al.$^{31}$ highlighted new evidence on the controversial topic of whether non-steroidal anti-inflammatory drugs may protect against AD. It was found that there was a dose-response effect with the long-term use of non-steroidal anti-inflammatory drugs, specifically ibuprofen, for lowering the risk for $\mathrm{AD}$. According to the study by Kivipelto et al., ${ }^{16}$ the APOE 44 allele was an independent risk factor for dementia/AD even after adjustments for socio-demographic, lifestyle and vascular factors. Among the APOE\&4 carriers, physical activity, alcohol drinking and smoking increased the risk of dementia/AD. In APOE 4 carriers this increased risk of dementia was associated with low-moderate intake of polyunsaturated and moderate-high intake of saturated fats. ${ }^{16,43}$ Additionally, a composite effect of lifestyle factors was seen among the $\varepsilon 4$ carriers. Kivipelto et al. ${ }^{16}$ concluded that APOE\&4 carriers may be more vulnerable to environmental factors and thus lifestyle interventions might modify dementia risk, particularly among genetically susceptible individuals. This has been supported by studies which show that other genetic risk factors influence the vulnerability of the central nervous system to the development of $\mathrm{AD}$ and includes genes involved with cholesterol and amyloid metabolism, microtubular associated protein tau, inflammatory factors and others. ${ }^{43}$ These risk factors for $\mathrm{AD}$ and dementia are of particular importance for baby boomers in Australia. In Western Australia, $25 \%$ of baby boomers are currently smoking, $14 \%$ are consuming risky or high levels of alcohol, $67 \%$ are inactive or undertaking low levels of exercise, and $51 \%$ are overweight or obese, with a similar pattern in Queensland and South Australia. High rates of cholesterol and hypertensive disease are also present in Australian baby boomers. Our emphasis of the importance of lifestyle risk factors on the development of $\mathrm{AD}$ in younger adults is supported by other investigators. ${ }^{44}$

\section{Conclusions}

There is limited data on the health of baby boomers at a national level in Australia. Important ABS data has been gathered in Western Australia, Queensland and South Australia; however, data for the most populated areas of Australia (New South Wales and Victoria, where the risk of dementia development is of greatest potential economic impact) are not available. We recommend that data be collected at a national level in order to better determine the level of risk of dementia of our baby boomers and to provide a foundation for prevention. We have not demonstrated statistically significant differences in risk factors or dementia prevalence and incidence for Western Australia, South Australia and Queensland. Further studies might help to address the role of genetic and lifestyle risk factors in those under 65 years in comparison with those over 65 years in the Australian states. This paper has shown that there are a myriad of factors which may impact on the risk of dementia, including genetic and non-genetic. Whilst associations with dementia have not been proven, we recommend that those variables which promote a healthy lifestyle should be adopted. Target populations include those baby boomers with mild cognitive impairment where stringent application of risk factor modification might prevent transformation to dementia. ${ }^{45}$ However, in our experience mild cognitive impairment is found in only $4.9 \%$ of younger adults with the suspicion of dementia. ${ }^{46}$ We propose that activities promoting a healthy heart will lead to a healthy brain. These might help to prevent dementia and are probably best incorporated into health promotion, prevention and early intervention programs in primary practice. ${ }^{47}$

\section{References}

1. Alzheimer's Association. 2008 Alzheimer's disease facts and figures. Alzheimers
Dement 2008;4:110-33.

2. Australian Bureau of Statistics. National Health Survey: Summary of Results 20042005, Catalogue No. 4364.0 (February 2006).

3. Plassman BL, Langa KM, Fisher GG, et al. Prevalence of dementia in the United States: the aging, demographics and memory study. Neuroepidemiology 2007;29:125-32.

4. Bynum JPW, Rabins PV, Weller W, et al. The relationship between dementia diagnosis, chronic illness, Medicare expenditures and hospital use. J Am Geriatr Soc 2004;52:187-94.

5. Stern Y, Gurland B, Tatemichi TK, et al. Influence of education and occupation on the incidence of Alzheimer's disease. JAMA. 1994;271:1004-10.

6. Evans DA, Herbert LE, Beckett LA, et al. Education and other measures of socioeconomic status and risk of incident Alzheimer disease in a defined population of older persons. Arch Neurol 1997;54: 1399-405.

7. Callahan CM, Hall KS, Hui SL, et al. Relationship of age, education and occupation with dementia among a community-based sample of African Americans. Archives of Neurology 1996;53:134-40.

8. Ngandu T, Von Strauss E, Helkala E, et al. Education and dementia: what lies behind the association? Neurology 2007;69:1442-50.

9. Kaiser S, Panegyres PK. The psychosocial impact of young onset dementia on spouses. Am J Alzheimers Dis Other Demen 2007;21:398-402.

10. Australian Bureau of Statistics. Population by Age and Sex, Australian States and Territories June 2003, Catalogue No. 3201.0 (June 2003).

11. Australian Bureau of Statistics (a). Western Australia's Baby Boomers: A Profile of Persons Born 1946-1965, Catalogue No. 4149.5 (June 2003).

12. Australian Bureau of Statistics (b). South Australia's Baby Boomers: A Profile 2003, Catalogue No. 4149.4.55.001 (November 2003).

13. Australian Bureau of Statistics (c). Baby Boomers in Queensland: A Profile of Persons Born 1946-1965, Catalogue No. 4149.3 (September 2005).

14. Access Economics, Dementia Estimates and Projections: Australian States and Territories, Report for Alzheimer's Australia, February 2005.

15. Fratiglioni L, Winblad B, von Strauss E. Prevention of Alzheimer's disease and dementia: major findings from the Kungsholmen Project. Physiol Behav 2007; 92:98-104.

16. Kivipelto M, Ngandu T, Laatikainen T, et al. Risk score for the prediction of dementia risk in 20 years among middle aged peo- 
ple: a longitudinal, population-based study. Lancet Neurol 2006;5:735-41.

17. Peters R, Beckett N, Forette F, et al. Incident dementia and blood pressure lowering in the Hypertension in the Very Elderly Trial cognitive function assessment (HYVET-COG): a double-blind, placebo controlled trial. Lancet Neurol 2008;7: 683-9.

18. Whitmer RA, Gustafson DR, BarrettConnor E, et al. Central obesity and increased risk of dementia more than three decades later. Neurology 2008;71: 1057-64.

19. Andel R, Crowe M, Pedersen NL, et al. Physical exercise at midlife and risk of dementia three decades later: a population-based study of Swedish twins. J Gerontol A Biol Sci Med Sci 2008;63:62-6.

20. Harwood D, Barker W, St. George-Hyslop P, et al. Impact of alcohol use, smoking and Apolopoprotein-E epsilon 4 allele (APOE 4) on age of onset of late onset Alzheimer's disease. Abstract presented at the American Academy of Neurology Conference (Chicago, 16 April 2008).

21. Reitz C, den Heijer T, van Duijn C, et al. Relation between smoking and risk of dementia and Alzheimer disease: The Rotterdam Study. Neurology 2007;69:9981005 .

22. Mortimer JA, French LR, Hutton JT, Schuman LM. Head injury as a risk factor for Alzheimer's disease. Neurology 1985; 35:264-7.

23. Mortimer JA, van Duijn CM, Chandra V, et al. Head trauma as a risk factor for Alzheimer's disease: A collaborative reanalysis of case-control studies. Int $\mathrm{J}$ Epidemiol 1991;20:S28-35.

24. Fleminger $\mathrm{S}$, Oliver DL, Lovestone $\mathrm{S}$, et al. Head injury as a risk factor for Alzheimer's disease: The evidence 10 years on; a partial replication. J Neurol Neurosurg Psychiatry 2003;74:857-62.

25. Wilson RS, Scherr PA, Schneider JA, et al. Relation of cognitive activity to risk of developing Alzheimer disease. Neurology 2007;69:1911-20.
26. Verghese J, LeValley A, Derby C, et al. Leisure activities and the risk of amnestic mild cognitive impairment in the elderly. Neurology 2006;66:821-7.

27. Wang JY, Zhou DH, Li J, et al. Leisure activity and risk of cognitive impairment: the Chongqing aging study. Neurology 2006;66:911-3.

28. Crowe M, Andel R, Pedersen NL, et al. Does participation in leisure activities lead to reduced risk of Alzheimer's disease? A prospective study of Swedish twins. J Gerontol B Psychol Sci Soc Sci 2003;58:P249-55.

29. Scarmeas N, Levy G, Tang MX, et al. Influence of leisure activity on the incidence of Alzheimer's disease. Neurology 2001;57:2236-42.

30. Wang HX, Karp A, Winbald B, et al. Latelife engagement in social and leisure activities is associated with a decreased risk of dementia: a longitudinal study from the Kungsholmen Project. Am J Epidemiol 2002;155:1081-7.

31. Vlad SC, Miller DR, Kowall NW, et al. Protective effects of NSAIDs on the development of Alzheimer disease. Neurology 2008;70:1672-7.

32. Singh-Manoux A, Sabia S, Lajnef M, et al. History of coronary heart disease and cognitive performance in midlife: the Whitehall II study. Eur Heart J 2008;29: 2100-7.

33. Guo Z, Fratiglioni L, Viitanen M, et al. Apolipoprotein E genotypes and the incidence of Alzheimer's disease among persons aged 75 years and older: variation by use of antihypertensive medication? Am J Epidemiol 2001;153:225-31.

34. Qiu C, Winblad B, Fastbom J, et al. Combined effects of APOE genotype, blood pressure and antihypertensive drug use on incident AD. Neurology 2003;61:655-60.

35. Xu WL, Qiu CX, Wahlin A, et al. Diabetes mellitus and risk of dementia in the Kungsholmen project: a 6-year follow-up study. Neurology 2004;63:1181-6.

36. Ikram MA, van Oijen M, de Jong FJ, et al. Unrecognized myocardial infarction in rela- tion to risk of dementia and cerebral small vessel disease. Stroke 2008;39:1421-6.

37. Deschaintre Y, Richard F, Leys D, et al. Treatment of vascular risk factors is associated with slower decline in Alzheimer disease. Neurology 2009;73:674-80.

38. Duron E, Rigaud AS, Dubail D, et al. Effects of antihypertensive therapy on cognitive decline in Alzheimer's disease. Am J Hypertens 2009;22:1020-4.

39. Irie F, Fitzpatrick AL, Lopez OL, et al. Enhanced risk for Alzheimer disease in persons with type 2 diabetes and APOE epsilon4: The Cardiovascular Health Study Cognition Study. Arch Neurol 2008;65:89-93.

40. Cramer C, Haan MN, Galea S, et al. Use of statins and incidence of dementia and cognitive impairment without dementia in a cohort study. Neurology 2008;71:344-50.

41. Sparks DL, Kryscio RJ, Sabbagh MN, et al. Reduced risk of incident $\mathrm{AD}$ with elective statin use in a clinical trial cohort. Curr Alzheimer Res 2008;5:416-21.

42. Lautenschlager NT, Cox KL, Flicker L, et al. Effect of physical activity on cognitive function in older adults at risk for Alzheimer disease: a randomized trial. JAMA 2008;300:1027-37.

43. Stozická Z, Zilka N, Novák M. Risk and protective factors for sporadic Alzheimer's disease. Acta Virol 2007;51:205-22.

44. Patterson C, Feightner JW, Garcia A, et al. Diagnosis and treatment of dementia: 1 . Risk assessment and primary prevention of Alzheimer disease. CMAJ 2008;178:548-56.

45. Luck T, Luppa M, Briel S, et al. Incidence of mild cognitive impairment: a systematic review. Dement Geriatr Cogn Disord 2010; 29:164-75.

46. Panegyres PK, Frencham K. The course and causes of suspected dementia in young adults: A longitudinal study. Am J Alzheimers Dis Other Demen 2007;22:48-56.

47. Travers CM, Martin-Khan MG, Lie DC. Dementia risk reduction in primary care: what Australian initiatives can teach us. Aust Health Rev 2009;33:461-6. 